\title{
Occupational traumatic injuries rarely affect genitourinary organs: a retrospective, comparative study
}

\author{
Jessica L. Wenzel ${ }^{1}$ (1) - Ashley N. Dixon ${ }^{1} \cdot$ Anish B. Patel ${ }^{1} \cdot$ Jack C. Webb ${ }^{1} \cdot$ Praveen N. Satarasinghe $^{1} \cdot$ Sadia Ali $^{1}$. \\ Carlos V. R. Brown ${ }^{1}$. J. Stuart Wolf Jr. ${ }^{1}$ - E. Charles Osterberg ${ }^{1}$
}

Received: 11 February 2019 / Accepted: 30 April 2019 / Published online: 7 May 2019

○) Springer-Verlag GmbH Germany, part of Springer Nature 2019

\begin{abstract}
Purpose To determine the mechanisms of injury associated with occupational injuries (OI) to genitourinary (GU) organs and compare GU OIs with GU non-OIs.

Methods A single institution, retrospective study was conducted at a level 1 trauma center between 2010 and 2016 of all patients with GU injuries. OI was defined as any traumatic event that occurred in the workplace requiring hospital admission. Types of occupations were recorded in addition to the location of injury, mechanisms of injury, concomitant injuries, operative interventions, total cost, and mortality. GU OI patients were then compared to GU non-OI patients.

Results 623 patients suffered a GU injury, of which 39 (6.3\%) had a GU OI. Fall (43\%) was the most common mechanism of injury; followed by motor vehicle collision/motorcycle crash (31\%), crush injury (18\%), and pedestrian struck (8\%). The adrenal gland $(38 \%)$ and kidney $(38 \%)$ were the most commonly injured organs. There was no difference in mortality (13\% GU OI vs. $15 \%$ GU non-OI, $p=0.70)$ or total direct cost $(\$ 21,192 \pm 28,543$ GU OI vs. $\$ 28,215 \pm 32,332$ GU non-OI, $p=0.45$ ). Total costs were decreased with mortality from a GU injury (odds ratio (OR) 0.3 , CI $0.26-0.59 ; p=<0.001$ ) and increased with higher injury severity scores (OR 1.1, CI 1.09-1.2; $p=<0.0001$ ). Total costs were not affected by OI status. Conclusions Occupational GU trauma presents with similar patterns of injury, hospital course, and direct cost as GU trauma that occurs in non-occupational settings.
\end{abstract}

Keywords Occupation $\cdot$ Injury $\cdot$ Work related $\cdot$ Genitourinary $\cdot$ Cost $\cdot$ Trauma

$\begin{array}{ll}\text { Abbreviations } \\ \text { GU } & \text { Genitourinary } \\ \text { OI } & \text { Occupational injury } \\ \text { WC } & \text { Workers' compensation } \\ \text { US } & \text { United States Department of Labor }\end{array}$

\section{Introduction}

Occupational injury (OI) is defined as an event occurring during work activity that causes personal injury, disease or death [1]. OI caused approximately 5600 job-related deaths and 8.5 million non-fatal injuries in 2007 , although incidence has been declining [2-4]. In 2016, that number

Jessica L. Wenzel

jessicalreynoso@gmail.com

1 Dell Seton Medical Center, Dell Medical School, University of Texas, 1313 Red River Street, ANNEX Building, Suite A2, Austin, TX 78701, USA decreased to 5190 and 2.86 million, respectively [4]. However, accurate epidemiological data on OI are difficult to obtain due to various reporting modalities and incentives [5]. A capture-recapture analysis looking into OI incidence in Michigan found that up to $68 \%$ of injuries were not accounted for with the current surveillance systems [6]. Similarly, another capture-recapture analysis found nonfatal OI was reported in less than $50 \%$ of cases [7]. These underestimates indicate that less resources were allocated to preventing and addressing OIs than what is needed [5].

OI continues to have a substantial economic impact, which can be broken down into direct cost, or medical expenses including hospitalization and associated costs, and indirect cost, which includes lost productivity [2]. An estimate from 1997 placed the total annual cost of OI in the United States at $\$ 171$ billion, with a direct cost of $\$ 65$ billion and an indirect cost of $\$ 106$ billion [2]. In 2011, the total annual cost was estimated to have increased to $\$ 192$ billion, with direct and indirect costs of $\$ 6$ billion and $\$ 186$ billion, respectively [3]. 
Although OIs more commonly impact the musculoskeletal system or nervous system, leading to lower back strain/ sprains and/or neuropathy, more severe trauma may occur [8]. In these cases, patients may experience head injury, fracture, or intra-abdominal and pelvic injury [8]. To date, the impact of traumatic OI on the genitourinary (GU) system is unknown. Furthermore, the mechanisms of injury associated with $\mathrm{OI}$ to GU organs are unknown. Given the relative frequency of OI and the susceptibility of GU organs to traumatic injury, we sought to determine the most common GU organs injured following an OI, as well as the mechanism of injury, and compare the impact of GU injury in an occupational setting (GU OI) with GU injuries in a nonoccupational setting (GU non-OI) on cost, morbidity, and mortality.

\section{Materials and methods}

After Institutional Review Board approval was obtained, we retrospectively collected data on 623 patients with GU injury at a level 1 trauma center between 2010 and 2016 from our prospectively maintained trauma database. Data on both the GU OI and GU non-OI groups were collected from this inpatient database; all patients who had GU trauma were included.

Data was collected on patient demographics including age, sex, mechanism of injury, location of injury, concomitant injuries, injury severity score (ISS), operative interventions, total cost, and mortality. Traumatic injuries were reported using ICD9/10 codes and external injury codes 800-920. GU organ ICD9/10 codes used were kidney (866, S37.0, S37.01-.06, S37.69, S37.09, S37.99), ureter (867.2, 867.3, S37.1, S37.12, S37.13, S37.19), bladder and urethra (867.0, 867.1, .2, S37.22, S37.23, S37.29, S37.3, S37.32, S37.33, S37.39), prostate (S37.82, S37.822, S37.823, S37.828, S37.829), penis (878.0, 878.1, S39.94, S38.01, S38.22, S38.222), testes and scrotum (878.2, 878.3, S39.94, S38.02, S38.23), adrenal (S37.81, S37.812, S37.813, S37.819), all GU organ injuries (S37.89, S37.892, S37.893, S37.898, S37.899), labia injury (S39.94), vagina (S31.4, S31.43), and vulva (S38.03).

Type and location of occupation were also recorded. Categories for type of occupation were finance, manufacturing, retail, transportation, agriculture/fishing, professional/business, education/health, construction, government, natural resources/mining, information services, wholesale, leisure, and other; categories for location were farm, mine/quarry and industrial. Patients were categorized based on whether the GU trauma occurred in an occupational setting (GU OI), or a non-occupational setting (GU non-OI). OI was defined as any traumatic event that occurred in the workplace requiring hospital admission. Non-OI was defined as any traumatic event that occurred in any place other than the workplace.

Data on cost were collected from two different costing systems due to a shift at our hospital from a local costing system to a national costing system in fiscal year 2016 . The local costing system included all patients discharged before July 1, 2016; the national costing system included all patients discharged on July 1, 2016 or later. Using the local costing system, direct cost data on labor were collected using relative value units (RVUs) for surgical minutes, therapy, imaging, and the emergency department (ED); a ratio of cost to charge (RCC) method was used to calculate labor cost in pharmacy. Data on supply items for pharmacy, surgery, and contrast for imaging were collected using the RCC method. Direct cost data for all other expenses related to therapy, imaging and the ED were collected using RVUs. Using the national costing system, cost of labor for therapy, imaging, and the ED were collected by matching CPT codes to RVUs; to calculate cost for pharmacy, CPT codes were used to weigh labor needed to dispense medications based on the delivery method with RCC. Supply items and additional expenses for pharmacy, surgery, therapy, imaging, and the ED were matched to invoices and calculated with the RCC method. Cost data in nursing units and lab-related departments were collected from both systems using RVUs based on the CPT code of the charge for labor and RCC for all other expenses. Overhead cost was calculated using drivers, which allowed for individual allocation based on RCC; drivers included patient revenue, patient days, expense, and square footage. Both costing systems used a year to date cost; the local system was based on discharge date and the national system was based on posting date. Direct cost data included the ED and inpatient stay; the cost of follow-up and outpatient care was excluded as our database only captured inpatient costs.

Chi squared tests were used to compare categorical variables between GU OI and GU non-OI. $T$ tests were used to compare continuous variables between GU OI and GU non-OI. Multilevel logistic regression was used to compare mortality with cost and differences amongst subgroups; $p<0.05$ was considered statistically significant. All statistical analysis was performed with SAS (v. 9.4).

\section{Results}

From 2010 to 2016, 623 patients suffered a GU injury, of which 39 (6.3\%) presented with GU OI and 584 (93.7\%) had a GU non-OI. 


\section{Demographics}

There were no significant differences in age $(39 \pm 17$ years non-OI vs. $39 \pm 13$ years GU OI, $p=0.86$ ) nor ethnicity; however, the majority of GU OI occurred in men compared to GU non-OI (38 (97\%) vs. 422 (72\%), respectively, $p<0.001$ ) (Table 1).
Mechanism of injury, occupation, and location of accident

Following chart review, fall was the most common mechanism of injury $(17 / 39,43 \%)$, followed by motor vehicle/ motorcycle crash $(12 / 39,31 \%)$, crush injury $(7 / 39,18 \%)$, and struck pedestrian $(3 / 39,8 \%)$. All GU OI injuries occurred from blunt trauma. Data on occupation were
Table 1 Demographics, organs injured, and clinical outcomes of patients with genitourinary occupational injury versus genitourinary non-occupational injury

\begin{tabular}{|c|c|c|c|}
\hline $\begin{array}{l}\text { Genitourinary injury, } N=623 \text {, } \\
N(\%) \text { or mean (SD) }\end{array}$ & GU non-OI, $N=584$ & GU OI, $N=39$ & $P$ value \\
\hline Age & $39 \pm 17$ & $39 \pm 13$ & 0.86 \\
\hline Male & $422(72)$ & $38(97)$ & 0.0005 \\
\hline White & $392(67)$ & $21(54)$ & 0.09 \\
\hline \multicolumn{4}{|l|}{ Organs injured } \\
\hline Adrenal & $142(24)$ & $15(38)$ & 0.049 \\
\hline Right & $*$ & $12(80)$ & \\
\hline Left & $*$ & $1(7)$ & \\
\hline Bladder & $120(21)$ & $10(26)$ & 0.45 \\
\hline Intraperitoneal & $*$ & 0 & \\
\hline Extraperitoneal & $*$ & $3(30)$ & \\
\hline Kidney & $310(53)$ & $15(38)$ & 0.08 \\
\hline Grade I & $*$ & $5(33)$ & \\
\hline Grade II & $*$ & 0 & \\
\hline Grade III & $*$ & $2(13)$ & \\
\hline Grade IV & $*$ & 0 & \\
\hline Grade V & $*$ & $1(7)$ & \\
\hline Labia & $4(0.68)$ & 0 & 0.60 \\
\hline Penis & $10(2)$ & 0 & 0.41 \\
\hline Prostate & $12(2)$ & 0 & 0.37 \\
\hline Testes & $27(5)$ & $4(10)$ & 0.12 \\
\hline Ureter & $14(2)$ & 0 & 0.33 \\
\hline Urethra & $*$ & $8(21)$ & \\
\hline Vagina & $9(2)$ & 0 & 0.43 \\
\hline Vulva & $3(0.51)$ & 0 & 0.65 \\
\hline \multicolumn{4}{|l|}{ Clinical outcomes } \\
\hline ISS & $24 \pm 15$ & $21 \pm 12$ & 0.25 \\
\hline Hospital LOS & $12 \pm 14$ & $10 \pm 8$ & 0.35 \\
\hline ICU LOS & $3 \pm 7$ & $2 \pm 5$ & 0.45 \\
\hline Ventilation days & $2 \pm 5$ & $2 \pm 4$ & 0.56 \\
\hline Mortality & $88(15)$ & $5(13)$ & 0.70 \\
\hline Workers' compensation & $2(0.34)$ & $22(56)$ & $<0.0001$ \\
\hline Total direct cost & $\$ 28,215 \pm 32,332$ & $\$ 21,192 \pm 28,543$ & 0.45 \\
\hline Discharge disposition & & & 0.80 \\
\hline Home & $376(66)$ & $25(64)$ & \\
\hline Skilled nursing facility & $36(6)$ & $2(5)$ & \\
\hline Rehabilitation & $72(13)$ & $7(18)$ & \\
\hline Died & $85(15)$ & $5(13)$ & \\
\hline
\end{tabular}

GU non-OI genitourinary non-occupational injury, includes all patients who suffered GU trauma in a non-occupational setting, $G U$ OI genitourinary occupational injury, includes all patients who suffered GU trauma in an occupational setting

*Data not available 
available in 30/39 (77\%) GU OI patients. The top occupations for GU OI were construction $(14 / 39,36 \%)$, transportation/public utilities $(7 / 39,18 \%)$, and other $(4 / 39,10 \%)$. Accident location was listed in $11 / 39$ (28\%) patients. Industrial work places were the most common (10/39, $26 \%$ ) followed by mine/quarry $(1 / 39,3 \%)$ (Table 2 ).

\section{Genitourinary organs injured}

Among both GU OIs and GU non-OIs, the most commonly injured GU organs were the kidney and adrenal gland (Table 1). There was no difference in incidence among renal injuries between the groups [GU OI 15/39 (38\%) vs. GU non-OI 310/584 (53\%), $p=0.08$ ]. In GU OI, Grade $1(5 / 15,33 \%)$ was the most commonly reported; renal trauma grade was unavailable in the GU non-OI group. There was a higher incidence of adrenal injuries in GU OI when compared to GU non-OI [15/39 (38\%) vs. $142 / 584$ (24\%), respectively, $p=0.049$ ]. In adrenal OI, $12 / 15(80 \%)$ were right sided, $1 / 15(7 \%)$ was left sided, and data on laterality were unavailable in $2 / 15$ (13\%). There were no significant differences in injury rate of the bladder, ureter, prostate, penis, labia, vagina or vulva between the groups.

Table 2 Mechanism of injury, occupation, and location of accident of genitourinary occupational injury patients

\begin{tabular}{ll}
\hline & $N(\%)$ \\
\hline Mechanism of injury & \\
Motor vehicle collision/MCC & $12(31)$ \\
Fall & $17(43)$ \\
Pedestrian struck & $3(8)$ \\
Crush injury & $7(18)$ \\
Occupation & \\
Finance & 0 \\
Manufacturing & 0 \\
Retail & 0 \\
Transportation/public utilities & $7(18)$ \\
Agriculture & $3(8)$ \\
Education & 0 \\
Construction & $14(36)$ \\
Government & $2(5)$ \\
Mining & 0 \\
Technology & 0 \\
Other & $4(10)$ \\
Location of accident & \\
Farm & 0 \\
Mine/quarry & $1(3)$ \\
Industrial place & $10(26)$ \\
\hline
\end{tabular}

\section{Hospital stay, outcomes, and costs}

There were no differences in ISS, hospital length of stay (LOS), intensive care unit days, ventilation days, mortality, or total direct cost between GU OIs and GU non-OIs (Table 1). Twenty-one percent (8/39) of GU OI required operative intervention for their GU injuries. Less than $1 \%$ (2/584) of GU non-OI patients received workers' compensation (WC) compared to $56 \%$ (22/39) GU OI patients $(p<0.0001)$. Total costs were decreased with mortality from a GU injury (odds ratio (OR) 0.3 , CI $0.26-0.59 ; p=<0.001$ ) and increased with higher ISS (OR 1.1, CI 1.09-1.2; $p=<0.0001$ ). Total costs were not affected by occupational status. Of those patients who suffered a GU OI, 64\% (25/39) were discharged home, $20 \%(8 / 39)$ to a rehabilitation facility, and 3\% (1/39) to a skilled nursing facility (Table 2).

\section{Discussion}

GU OIs primarily occured among males in an industrial setting, via fall leading to blunt trauma, with the adrenal gland and kidney mostly affected. We found no difference in ISS, hospital or ICU LOS, number of days on ventilation, mortality, or total cost between GU OIs and GU non-OIs.

Although adrenal trauma is typically rare, with estimated incidence of $2 \%$ or less in blunt abdominal trauma, our study found higher rates in both GU OI (38\%) and GU non-OI patients (24\%) [9]. Conversely, a large prospective study in Taiwan found that $77 / 9252(0.83 \%)$ patients with blunt abdominal trauma had an adrenal injury, with 59/77 (77\%) and 16/77 (20.8\%) of injuries occurring on the right and left sides, respectively [10]. Their cohort had a similar mean ISS $(25.4 \pm 13.4)$, implying that injury severity did not impact the adrenal trauma incidence rate discrepancy. It is possible that the high rate in our cohort is due to ICD coding bias captured solely based on imaging or intraoperative findings. It is worth noting that GU OI patients in our study had a significantly higher incidence of adrenal trauma than GU non-OI patients, although this may be related to a small sample size as opposed to a true difference. However, it is also possible that patients with OI had higher velocity or higher impact injuries than non-OI. Additionally, the laterality of injury seen in our study aligns with previous findings with higher rates of injury to the right adrenal gland. This suggests underlying factors that favor right-sided injury such as shorter, more vulnerable adrenal vein to the vena cava.

Friedman et al. evaluated traumatic OIs of any type utilizing the Illinois Trauma Registry between 1995 and 2003 [11]. In their study, most OIs occurred in men $(86.6 \%$; $N=19,532)$. The authors found that the most common causes of injury were falls $(34.8 \%, N=7845)$, machinery $(18.1 \%, N=4088)$, and motor vehicle crashes $(11.2 \%$, 
$N=2532$ ). While the authors did not note specific organs injured, they did report an internal injury rate of $15.4 \%$ $(N=3462)$. Injured workers were hospitalized for 3.6 days $(\mathrm{SD}=7.5)$, stayed in the ICU for $0.7(\mathrm{SD}=3.4)$, and required ventilator support for 0.3 days $(\mathrm{SD}=2.4)$. There are some similarities with our findings in which patients suffering from an OI were more likely to be male and suffer from a fall. However, we found a higher ISS among GU OI patients, longer hospital stays, longer ICU stays and required ventilator support. The higher ISS of our cohort likely contributed to the increased duration of hospitalization, ICU days, and ventilator support. Because our patients who experienced GU non-OI also had higher ISS than those in the study by Friedman et al., the differences in care required are more likely due to higher acuity and not due to higher severity in GU OI specifically.

The United States Department of Labor (USDOL) mandates strict requirements to qualify for worker's compensation. Because the occurrence of injury must be directly related to performance of occupational duty to be eligible for this benefit, it is unsurprising that our study found a lower rate of utilization of WC amongst the GU non-OI group when compared to the GU OI group [12]. In other words, patients meeting the USDOL eligibility for WC were injured at work, leading to nearly exclusive classification into our GU OI group, thus creating a significant difference between groups. Laws regarding WC are on a state-by-state basis, with every state except Texas requiring an employer to offer coverage [13]. Biddle et al. analyzed the percentage of workers in Michigan who utilized WC after an OI. They found overall low rates of utilization ranging from 10 to $45 \%$ of eligible workers, with slightly higher rates among women [14]. Another study conducted by the CDC investigated use of WC in ten different states and found higher utilization rates, ranging from $47 \%$ (Texas) to $77 \%$ (Kentucky) [15]. Despite all cases in our study occurring in Texas, we still found a higher utilization of WC among those with GU OIs when compared to expected rates. Because the study by Biddle et al. did not account for injury severity, it is possible that their lower rates of utilization are due in part to lower reporting among less severe conditions, such as muscle sprains, and the higher rates we found were biased by traumatic injuries with higher acuity. However, it is also possible that patients who experience a GU OI have a higher rate of utilization of WC than other types of OI. A possible explanation is that GU OI patients, when compared with those who experience OI without GU injury, are more likely to experience polytrauma and greater injury severity and are thus more likely to require disability compensation [16].

In comparing cost data, evidence has shown that patients covered by WC are charged significantly more than patients with comparable injuries not utilizing WC [17]. Our data found no cost difference between GU OI and GU non-OI and utilization of WC. While we only looked at inpatient and direct cost, Baker et al. speculate that most of the difference arises in indirect cost. However, most patients in our cohort were discharged home, with fewer patients requiring rehabilitation or admission to a skilled nursing facility, suggesting less cost to the healthcare system. Nevertheless, this does not account for the lost productivity after discharge, which could also be factored into indirect cost and is an area among GU OI patients that could be further explored.

Aside from being a single center study, our study has several limitations. We only accounted for data from a single region, Central Texas; due to variance in OIs based on region of occurrence, this makes our study less generalizable on a national scale. It is small with low power for our comparative analysis. Additionally, the retrospective nature of our study limited data collection and completeness; data on occupation and location of accident were particularly difficult variables to obtain. Furthermore, we were unable to review outpatient cost or determine the long-term impact that GU OI had on the patients' ability to earn an income or time required away from work.

\section{Conclusions}

To our knowledge, this is the first study on the impact of occupational trauma on genitourinary injuries. GU OI appears to result from the same common mechanisms that have been previously described in other studies and to also have a significant economic burden with higher WC utilization. While our study did not determine any differences between GU OI and GU non-OI, further research should be conducted to assess differences in management, income loss, and long-term disability.

Author contributions JLW: Data collection, manuscript writing/editing. AND: project development, data collection, manuscript writing/editing. ABP: data collection, manuscript writing/editing. JCW: manuscript writing/editing. PNS: manuscript writing/editing. SA: data analysis. CVRB: manuscript writing/editing. JSW: manuscript writing/editing. ECO: project development, data collection, manuscript writing/editing.

Funding There is no funding to disclose.

\section{Compliance with ethical standards}

Conflicts of interest The authors declare that they have no conflict of interest.

Ethical approval All procedures performed in studies involving human participants were in accordance with the ethical standards of the institutional and/or national research committee and with the 1964 Helsinki Declaration and its later amendments or comparable ethical standards. 
Informed consent This is a retrospective review. For this type of study formal consent is not required.

\section{References}

1. OECD Statistics Directorate. OECD Glossary of statistical terms - occupational injury definition. https://stats.oecd.org/gloss ary/detail.asp?ID=3565. Accessed 25 May 2018

2. Leigh JP (1997) Occupational injury and illness in the United States. Estimates of costs, morbidity, and mortality. Arch Intern Med 157(14):1557-1568. https://doi.org/10.1001/archi nte.157.14.1557

3. Leigh JP (2011) Economic burden of occupational injury and illness in the United States. Milbank Q 89(4):728-772. https://doi. org/10.1111/j.1468-0009.2011.00648.x

4. Injuries, illnesses, and fatalities. US Bureau of Labor Statistics. https://www.bls.gov/iif/home.htm. Accessed Oct 22, 2018

5. Leigh JP, Marcin JP, Miller TR (2004) An estimate of the US Government's undercount of nonfatal occupational injuries. J Occup Environ Med 46(1):10-18. https://doi.org/10.1097/01.jom.00001 05909.66435.53

6. Rosenman KD, Kalush A, Reilly MJ, Gardiner JC, Reeves M, Luo Z (2006) How much work-related injury and illness is missed by the current national surveillance system? J Occup Environ Med 48(4):357-365. https://doi.org/10.1097/01.jom.0000205864 .81970 .63

7. Boden LI (2013) Capture-recapture estimates of the undercount of workplace injuries and illnesses: sensitivity analysis. Am J Ind Med 57(10):1090-1099. https://doi.org/10.1002/ajim.22247

8. Courtney TK, Matz S, Webster BS (2002) Disabling occupational injury in the US construction industry, 1996. J Occup Environ Med 44(12):1161-1168. https://doi.org/10.1097/00043764-20021 2000-00010

9. Lin YH, Wu T (2013) Isolated adrenal hemorrhage after blunt trauma: case report and literature review. Urol Sci 24(1):27-29. https://doi.org/10.1016/j.urols.2013.01.002
10. Liao C-H, Ouyang C-H, Fu C-Y et al (2015) The current status and management of blunt adrenal gland trauma. Surgery 157(2):338 343. https://doi.org/10.1016/j.surg.2014.09.001

11. Friedman LS, Forst L (2007) Occupational injury surveillance of traumatic injuries in Illinois, using the illinois trauma Registry: 1995-2003. J Occup Environ Med 49(4):401-410. https://doi. org/10.1097/jom.0b013e31803b9527

12. Sengupta I, Reno V (2007) Recent trends in workers' compensation. Soc Secur Bull 67:17-26

13. United States Department of Labor: frequently asked questions. Webapps.dol.gov. https://webapps.dol.gov/dolfaq/. Published 2019. Accessed 31 Jan 2019

14. Biddle J, Roberts K, Rosenman KD, Welch EM (1998) What percentage of workers with work-related illnesses receive workers compensation benefits? J Occup Environ Med 40(4):325-331. https://doi.org/10.1097/00043764-199804000-00006

15. Bonauto DK, Fan JZ, Largo TW, Rosenman KD, Green MK, Walters JK, Materna BL, Flattery J, St. Louis T, Yu L, Fang S, Davis LK, Valiante DJ, Cummings KR, Hellsten JJ, Prosperie SL (2010) Proportion of workers who were work-injured and payment by workers' compensation systems-10 States, 2007. Morb Mortal Wkly Rep 59:897-900

16. Tezval H, Tezval M, von Klot C, Herrman TR, Dresing K, Jonas U, Burchardt M (2007) Urinary tract injuries in patients with multiple trauma. World J Urol 25(2):177-184. https://doi.org/10.1007/ s00345-007-0154-y

17. Baker LC, Krueger AB (1995) Medical costs in workers compensation insurance. J Health Econ 14(5):531-549. https://doi. org/10.1016/0167-6296(95)00020-8

Publisher's Note Springer Nature remains neutral with regard to jurisdictional claims in published maps and institutional affiliations. 